\title{
Ethical Extensionism under Uncertainty of Sentience: Duties to Non-Human Organisms without Drawing a Line
}

\begin{abstract}
Ethical extensionism generally involves drawing one or more lines of moral standing. I argue (i) for all living organisms, there is a non-zero probability of sentience and consciousness, and (ii) we cannot justify excluding beings from consideration on the basis of uncertainty of their sentience, etc., and rather we should incorporate this uncertainty into the strength of our moral responsibilities. This use of probabilities differs critically from multi-criteria theories of moral standing and those that assign benefit of the doubt, which involve unjustified exclusions and dilutions of duties. From uncertainty rises certainty: we have duties to non-human organisms, although they may often be minor. This modification of extensionist ethics provides foundation for an environmental ethic that parallels interpersonal and animal welfare ethics, and it suggests that we owe much greater concern to 'lower' organisms than they are typically given.
\end{abstract}

Key words: moral considerability; extensionism; moral standing; consciousness; uncertainty; the Golden Rule.

\section{Introduction}

Attempts to provide moral justification for duties to non-human organisms have generally come up short. One kind of attempt (extensionism) has generally excluded all but a subset of animals from moral consideration, which conflicts with a commonly held carefully considered belief that 
even 'lower' animals and plants deserve some consideration. Extension arguments include Peter Singer's $(1979 ; 1991 ; 1993)$ attribution of moral standing to animals deemed 'sentient' and Tom Regan's (1983) attribution of moral standing to animals deemed 'subjects of a life', and a second generation of philosophers including Midgley (1998), Sapontzis (1992), and DeGrazia (1996).

Largely in response to a perceived failure of extensionist ethics, a second kind of attempt (biocentrism) has generally tied moral standing to some characteristic or process of unjustified moral relevance (e.g., life, natural selection). Here we have Paul Taylor's (1986) respect for nature, Varner's (1998) theory of biological interests, Rolston's (1988) and Callicott's (1985) theories of intrinsic value of living beings, and Attfield's (1999) biocentric consequentialism. All of these theories are claimed to justify moral standing for all living beings, but each has been critiqued for its failure to rigorously connect these non-desire based notions of welfare or a good of one's own to moral consideration (Regan 1992).

A second obstacle facing biocentric theories is the problem of integrating competing duties from biocentric and anthropocentric ethics. Because biocentric ethics begin from such different premises than interpersonal ethics, any comprehensive biocentric ethic must provide not only solid justification for biocentrism but also a framework for determining when and to what extent biocentric duties should outweigh anthropocentric ones, and vice versa.

Biocentric ethics may well overcome these challenges and finding a right relationship with the natural world may require biocentric ethics, but new understandings of traditionally accepted ethics will have force for the billions of people who subscribe to these ethics. Any biocentric duties to non-human organisms might add to extensionist duties, so consideration of extensionist arguments should not be seen as diminishing the importance of biocentric ethics. I therefore 
consider the possibility that ethical extensionism might support duties to a much broader set of non-human organisms than generally thought.

My argument is rooted in a novel use of uncertainty, such that uncertainty of a being's sentience modifies the strength of duties to that organism. Several authors have directly addressed the uncertainty of sentience or consciousness in animals (Dawkins 1980; Griffin 2001; Warren 1997; Wise 2002). Yet the prevalent tendency has been to use that uncertainty to 'draw the line' more precisely, thus turning a continuous variable into a categorical one and losing crucial information. ${ }^{1}$ I argue that to avoid unfair exclusions and unjustified dilution of duties, we must retain the gradations of uncertainty and employ this information to adjust the strength of our duties to organisms. This apparently innocuous treatment of uncertainty has crucial implications when applied to the apparent interests of non-human organisms, and it may transform traditional ethics into a palatable environmental ethic.

\section{The Structure of the Argument}

The forthcoming argument has many necessary steps. Some elements occur elsewhere, but because of the crucial role of each in supporting subsequent steps and conclusions, I present the argument in full with justifications for all preliminary steps. Readers who find individual steps unproblematic can skip these sections and return to skipped sections as necessary.

A. Anything might be considered an 'other' under ethical theories.

B. We should have good reasons for excluding any entity from moral consideration. 
C. The lack of mental experience is a common and central reason to exclude entities from moral consideration.

D. Sentience (as possessing a 'point of view') is a mental phenomenon that we cannot observe directly, only through physical structures and processes, so we cannot be certain that non-human organisms do not have points of view. In fact, their behaviors suggest that they may, with varying strength of evidence and so estimated probability.

E. Under a procedural application of the Golden Rule, uncertainty of sentience cannot justify either lack of consideration or equal treatment. Rather, we have duties to a nonhuman organism in proportion to the probability that it is sentient.

F. In addition to a being's proximate interests (e.g., avoiding pain), we should respect its apparent ultimate interests (e.g., survival and reproduction); that respect should be proportional to the probability that the being is conscious; and the importance of an interest to an organism is indicated by the strength and amount of striving for the 'goal'.

G. To avoid moral paralysis, we should draw a practical line: we should not try to consider entities that do not provide some indication of what their interests might be.

H. The minimum evidence for the proposition that a being might be sentient is also sufficient to raise the possibility that the being is also conscious. Based on the available evidence, the probability of sentience and consciousness may be very low in many organisms, but it is nonzero, which is sufficient to have ethical ramifications when resulting duties are aggregated. 
I. (interim conclusion) Therefore, we have duties to non-human organisms' proximate and (possible) ultimate interests, although these may often be insignificant individually.

J. (application) I apply this extensionist ethic by considering the different kinds and strengths of responsibilities to different organisms based on the level of evidence of their sentience, etc.

\section{The Supposed Problem: No Point of View? (A - D)}

"It is just like a man's vanity and impertinence to call an animal dumb because it is dumb to his

$$
\text { dull perceptions." - Mark Twain }
$$

Anything at all might be considered an 'other' under ethical theories - the primary task is to determine which of these others matter morally. If we agree with Birch (1993) that ethics is at its core universalizing (intended for broad application), we must have strong reasons to exclude entities. Others have argued for such a shift in approach to animals (from assuming that they do not possess minds such as ours until proven otherwise, to approaching them as animals with somewhat parallel minds) (e.g., Diamond 2008; Jamieson 2002), and here I consider the possibility and ramifications of extension to other non-human organisms.

Singer (1991) has argued persuasively that species identity (e.g., humanity) is insufficient and unjustifiable grounds for moral exclusion. A similar argument could be made for any physical criterion, such as possession of any particular physiological structure or set of structures: why should we require that an entity have any such particular physical criterion to consider it morally? If an entity has experiences, why should it matter what physical structures seem to give rise to 
such experiences? On the flip side, why should consider an entity morally if it possesses physical structures but not experiences? In the absence of a strong argument to this effect, I conclude that what matters is the possession of experiences—-what I refer to here as a "point of view".

The primary impediment to extending anthropocentric ethics to all non-human organisms is the notion that most organisms (all bacteria, plants, fungi, etc., and less complex animals) have no point of view. Even people who are willing to accept Taylor's (1986) plausible claim that living beings have a "good of their own" ${ }^{2}$ cannot motivate themselves to care about that 'good'. For example, even Peter Singer, who is famous for his extension of moral consideration to animals, wrote that "there is nothing that corresponds to what it is like to be a tree" (Singer 1993, p. 277) and "[i]f a being is not capable of suffering, or of experiencing enjoyment or happiness, there is nothing to be taken into account" (Singer 1991, p. 8). Singer's position is in keeping with Bentham's (1823, p.236), "the question is not, Can they reason? nor, Can they talk? but, Can they suffer?"

I do not here defend a particular definition of experience or point-of-view that would confer moral consideration, as my argument is applicable to many definitions. My concern here is to consider the extent to which interpersonal ethics—as people employ them — might provide basis for considering non-human organisms, not to establish a new ethical theory. For generally applicable shorthand, I therefore follow Singer (1993, p. 283-4) and adopt a definition of 'sentience' that is synonymous with possessing a point of view in the sense of a mental experience of some kind.

There is a problem with dismissing the vast majority of living beings on account of having no experience: we cannot know whether a being can experience some form of suffering, frustration, 
or enjoyment. Experience is a mental phenomenon that is crucial for ethical theories but which we cannot observe directly; all we can observe are the physical structures and processes that we hypothesize to be linked to the mental phenomenon (Dawkins 1980; Nagel 1974), but which are of no ethical significance alone. We cannot possibly determine that "there is nothing that corresponds to what it is like to be a tree". Physiological studies suggest that most organisms do not experience life in the way that we experience it based on the fact that most lack central nervous systems akin to ours and many lack recognizable nerve cells.

But physiological observations alone can neither prove nor disprove the existence of a point of view: we do not know that sentience is dependent upon particular physical structures (e.g., nerve cells), or that it cannot arise from sensory feedback processes based on hormones (which plants possess). We have reason to believe (but cannot be certain) that beings with similar structures have similar experiences, and we can only suspect that beings with different structures for sensing the world have different experiences or none at all. To attribute consciousness in another is to infer (Dennett 1991); the inference is based on some set of observations (evidence), but it also reaches beyond that evidence. And to assume no sentience in the face of some (inconclusive) evidence is to fail to imagine. Absence of evidence is not evidence of absence. Given the great diversity of ways that living beings operate, imagination of alternatives is critical to the fair assessment of likelihoods, and this must lead us to acknowledge non-zero probabilities of mental phenomena.

To recap the above argument briefly and in logical notation: sentience is a mental phenomenon apparently produced by physical structures. ${ }^{3}$ We have good reason to believe that human physical structures can produce sentience, and various human behaviors and physiological processes suggest that they do produce sentience in most human beings. We cannot rule out that other 
physical structures also produce sentience, although they vary in the likelihood that they do based on their complexity and organization. Our best estimate of the probability that a set of structures produces sentience is also a function of the behaviors and physiological processes of the organism. Sentience cannot be equated with particular physical structures.

Entities vary greatly in the extent to which they provide reason to believe in their sentience. We have little reason to believe that inanimate objects such as rocks (to which both Birch (1993) and Gorke (2003) attribute moral standing) can sense anything, because they cannot even act. Similarly, there is little reason to believe that viruses are sentient, as they have very limited responses to their environment and do not even possess the machinery or a contiguous location from which to expend their own energy. ${ }^{4}$

Most living things, however, provide much more reason to believe that they may be sentient. ${ }^{5}$ Even the simplest organisms respond in intricate ways to their environment and expend energy in pursuit of certain ends - thereby demonstrating that on one level outcomes matter to them. Plants orient themselves towards light or away from sources of mechanical damage, and some can even respond visibly to tactile stimulation towards identifiable "goals" (e.g., Venus flytraps, which trap insects for nutrient supplementation). They also selectively and actively absorb nutrients, and they repair damaged tissues. They even 'communicate' with each other through chemical compounds regarding the presence of natural enemies (Gershenzon and Dudareva 2007). Contrary to Feinberg (1974), it is certainly not ironic or metaphorical to speak of them flourishing, and furthermore it is not impossible that they have experiences. 
Regardless of the kinds of experiences or capabilities of experiences that are taken as morally relevant, we cannot rule out the possibility that many non-human organisms possess these experiences and capabilities.

\section{Responsibilities in the Face of Uncertainty (E, F)}

\section{Why modulate duties based on uncertainty (of sentience)?}

The typical response to uncertainty of sentience is to choose a threshold of some physical characteristic(s) above which beings are considered sentient and below which they are considered non-sentient. The search has been for the thresholds and characteristic(s) that best represent our understanding of the available evidence. "You have to draw the line somewhere," I have heard many times. Even when authors have represented uncertainty of sentience in quantitative terms, they have generally used this information to draw the line of consideration more rigorously or to draw multiple lines (Wise 2002).

I disagree: we do not have to draw 'the line' of sentience anywhere. To the contrary, since uncertainty regarding sentience is unavoidable, we should adopt principles that explicitly account for uncertainty in their prescriptions. We should do this to avoid excluding too much from consideration or granting too much to beings whose sentience is uncertain. Many others have argued for giving the benefit of the doubt, but the propagation of uncertainty argued for here differs starkly: it does not involve "giving them more than is their due" as Regan (1983, p.320) acknowledges of his 'benefit of the doubt'. Rather, by modulating duties based on uncertainty, we give moral patients exactly their due based on available evidence, acknowledging the considerable uncertainty therein. 
A morally relevant analogy demonstrates the logic and importance of the proposed manner of accounting for uncertainty. Imagine that a community living close to an oil refinery has found unacceptably high levels of some carcinogens in their soil and water, and that they have also suffered a statistically anomalous number of cancers. The oil company might be forced to compensate the community for both general harms like anxiety and relocation expenses and also particular harms, like health expenses to treat and cope with cancer. Imagine that a class action suit is successful, leaving a set pool of funds to be distributed among the claimants — a significant amount, but not sufficient to cover all the claimants' expenses. Statistically, some of these claimants had cancers that did not stem from the refinery, and based on the kinds of cancers and the times of their progression, some claimants are much more likely to have contracted their diseases as a result of the refinery than others. Just like with environmental ethical problems pertinent to this paper, a decision must be made, but it is currently unknowable whose cancers actually resulted from the refinery. It is, however, possible to estimate probabilities associated with these events based on epidemiological studies. Should the funds be given equally to all claimants, even though some had cancers that are highly unlikely to result from exposure to the relevant pollutants? Should the funds be given only to claimants above some threshold of likelihood, even though there is a smooth continuum of these likelihoods? I argue that the most just approach is to assign compensation to claimants in proportion to the best estimate of the likelihood that the claimant contracted his/her disease from exposure to the refinery's pollutants.

A second analogy reveals the benefits of modulating responsibilities based on uncertainty relative to ethical frameworks that assign kinds of responsibilities in a binary fashion (yes or no) based on the available evidence of various criteria, such as those of Warren (1997) and Varner (1998). As a parallel to the uncertainty that entities are sentient and so merit moral consideration, imagine a 
set of 11 people who may or may not have a disease - call it "lineitis" - that we can treat permanently with a pill. Just as there are tradeoffs in our moral decisions, we are forced to choose between these 11 patients for administering treatment: we have only 3 pills. Although their symptoms suggest that the probability that these people have lineitis varies uniformly $(0,0.1,0.2$, $\ldots, 1)$, draw-the-line approaches would have us determine a priori some threshold level of probability; patients with disease probabilities $(p(d))$ at or above this level would be considered "infected" and those with $p(d)$ below would be "uninfected". A reasonable threshold is 0.5 , so we have six people considered infected and five considered uninfected. If we don't modulate responsibilities based on the probabilities, we should then distribute the three pills at random among the "infected" persons. We'd expect this approach to effectively treat 2.25 people, an efficiency of 0.75 for the three pills.

The uncertainty-modulating alternative, on the other hand, would give one pill each to the three persons with the highest $p(d)$. We'd expect this approach to effectively treat 2.7 people, an efficiency of 0.9 for the three pills. The uncertainty-modulating approach therefore achieves a considerably higher efficiency than draw-the-line approaches. But the uncertainty-modulating approach really shines when there are large numbers of moral patients and variable costs of treatment.

The third analogy is the same as the second, with two substitutions. In place of person \#2, who had a $p(d)$ of 0.1 , are 1000 persons with the same $p(d)$ but a much greater sensitivity to treatment: each can be treated with $1 / 1000^{\text {th }}$ of a pill. This coincidence of low $p(d)$ with low costs of treatment is intended to be analogous to some decisions involving non-human organisms: organisms with low likelihood of sentience are often small, such that maintaining their survival 
might be relatively inexpensive. The second substitution is for person \#3, who had $p(d)$ of 0.2 : 100 persons with the same $p(d)$, but who can each be treated with $1 / 100^{\text {th }}$ of a pill.

The line-drawing approach is unchanged: because the threshold probability was 0.5 , we would not even consider treating the 1000 persons with $p(d)$ of 0.1 or the 100 persons with $p(d)$ of 0.2 . Again, we would expect this approach to effectively treat 2.25 people, an efficiency of 0.75 for the three pills.

The uncertainty-modulating approach would calculate the relative pay-offs of treating any of the patients, even if they are individually unlikely to have lineitis. By distributing one pill amongst the 1000 persons with $p(d)$ of 0.1 , one pill amongst the 100 persons with $p(d)$ of 0.2 , and one pill to the person with $p(d)$ of 1 , we would expect to effectively treat 121 people, an efficiency of $>40$ per pill. In the face of highly variable costs, benefits, and probabilities, modulating responsibilities based on probabilities can have an immense pay-off. In real moral dilemmas involving non-human organisms, both the probabilities of sentience and the resources needed to assist organisms are likely to vary over many orders of magnitude.

We might, however, accept this propagation of uncertainty in determining duties to people (who are widely accepted as moral patients), but reject it in the determining who merits moral consideration.

By applying the Golden Rule we find support for modulating moral considerability based on uncertainty. This nearly universal moral rule states variously that we should "do unto others as we would have them do unto us, were we in their position", or "love thy neighbor as thyself". Some version of this rule appears in most of the world's major religions, and virtually everyone 
agrees that it has important moral force: while it is assumed not to be a sufficient moral principle alone, few argue in favour of the moral acceptability of choices that fail by the Golden Rule.

In order to conform to the Golden Rule, the procedure we adopt for determining strength of duties must be one that we would want other-possibly more complex — beings to apply. Because we seem to be more complex mentally than other Earthly organisms, a hypothetical example is illustrative: consider how we would want aliens to treat many classes of beings, including us, given uncertainty of our sentience. Those of us who put stock in sentience as morally relevant would not want the aliens to give all entities the benefit of the doubt, treating all as if they were sentient. While this approach seems generous, it dilutes the fulfillment of responsibilities to beings with strong evidence of sentience by expending time and effort protecting the apparent interests of beings unlikely to be sentient. In reality, beings are either sentient or they are not, so the aliens would be 'kind' to many non-sentient objects; but because all decisions involve weighing costs and benefits to various entities, this generosity comes at the expense of sentient beings. On the other hand, we would not want the aliens to discount uncertain beings completely, as this might meant no consideration of our own preferences. The only satisfactory alternative is for them to weight equivalent interests of different beings by the evidence in favor of their sentience. ${ }^{6}$ According to the Golden Rule, we should therefore consider uncertainty in determining how we should treat non-human organisms.

\section{Who merits consideration?}

It may be impossible to put oneself in the position of an entity with no point of view, but we can put ourselves in the position of a being that might have a point of view. And to give beings their 
due in the face of uncertainty, we must do this: at this first stage, we cannot justify excluding any entity.

\section{What are our responsibilities to them?}

If we are to consider as moral patients a broad spectrum of living organisms - not just animals like us - it becomes less clear what our responsibilities might be to them.

The field of animal welfare has traditionally been concerned primarily with proximate interests that relate to affective states $^{7}$ (e.g., pain, hunger). If such goals are not fulfilled, animals that are deemed sentient demonstrate several symptoms that we may consider to connote suffering. Ultimate interests have generally been considered irrelevant to well-being except in the case of beings that have been shown conclusively to be conscious of those interests. ${ }^{8}$ Such beings, who are capable of mentally integrating behaviors and resulting consequences in light of desired states, I call conscious beings. This consciousness is considered to be a much higher bar than sentience; only certain 'higher' mammals and some birds are considered conscious, while most or all vertebrates and also some invertebrates are often considered sentient.

I tentatively accept the logic that proximate interests matter for sentient beings and ultimate interests matter for conscious beings, translated in terms of uncertainties: we have responsibilities to help fulfill or not impede the interests of non-human organisms; the strength of our duties to a non-human organism regarding its proximate interests (e.g., avoiding pain) is proportional to the probability of sentience; and the strength of our duties regarding its ultimate interests (e.g., survival and reproduction—see The Interests of Non-Human Organisms (H, I), below) is proportional to the probability of consciousness (see How to weigh their possible interests against those of others?.., below). These associations of sentience with proximate interests (e.g., hunger) 
and consciousness with ultimate interests (e.g., survival and reproduction-see The Interests of Non-Human Organisms (H, I)) are not arbitrary. If we knew that an organism could not experience hunger, what appears to be hunger seems not to matter intrinsically; and if an organism has no awareness of its life, survival seems of no import, in and of itself. Of course, biocentric ethics may reveal importance of survival, etc., even without sentience, but that is beyond the scope of the current paper.

The high bar of consciousness is partly a product of human chauvinism, and we should be open to consciousness that is unlike our cognitive rational consciousness. We typically assume that beings can only be aware of goals in the cognitive manner of human beings. This assumption flies in the face of psychological evidence that demonstrates a powerful influence of noncognitive factors on human decision-making (Loewenstein and O'Donoghue 2004; Milinski and Rockenbach 2007; Sanfey et al. 2006; Satpute and Lieberman 2006). We consider these noncognitive factors to be pre-conscious or sub-conscious, but clearly we are aware of them on important levels, just not always cognitively. It seems clear that these non-cognitive processes both form and assess our ultimate goals, and that they regulate the contribution of goals to happiness. In people, philosophers seem to assume that everything is integrated at the cognitive level. But it is also highly plausible that our cognitive processes have suppressed an awareness based on affective processes and that in other beings, analogous non-cognitive processes integrate a kind of awareness of ultimate goals that has an impact on a conscious well-being.

Indeed, the same animal behaviors that suggest sentience also suggest that there may be some consciousness of ultimate goals. Sentience must entail more than automatic response to the environment to have relevance for most ethical theories. But the same evidence that suggests that there is an experience of the environment beyond automation-highly contingent behaviors 
integrated towards apparent goals (see How to infer their possible interests?) —also suggests that there may be a kind of awareness of those goals: the contingency suggests that the being can sense changes in the environment, and complexity in resulting behavior patterns suggests that the being has an integrated awareness (one that integrates numerous kinds of internal and external sensory information to determine behaviour). The adaptability of wolf behavior in nurturing and protecting their pups (Packard 2003, p. 65) suggests a deep capacity for sensory integration; their ability to learn from experiences and observations (Packard 2003, p. 63) suggests a capacity for experiential integration across time and space. This kind of evidence may not conclusively demonstrate either sentience or consciousness, but it can suggest that both may be present. Thus, two mental capacities that seem deeply distinct under the typical demand for conclusive evidence seem rather more similar when we propagate uncertainty and treat beings according to strength of evidence rather than conclusive proof.

\section{How to infer their possible interests?}

To provide guidance regarding the inference of interests in organisms unlike us, it helps to consider how we would like aliens to infer our interests. Direct communication would be impossible, however, and imagination uninformed by data is too whimsical and inaccurate.

Instead, I argue that — allowing for the possibility that we are conscious — the aliens should take our striving at face value, and try to discern our ultimate goals from that striving. (The more uncertain that they are of our ultimate goals, the more they should simply consider it in our interests to be left alone to pursue our ends.) Since we would want others to treat us this way, to adhere to the Golden Rule ${ }^{9}$ we must treat others this way. 
I therefore argue that—acknowledging uncertainty about a being's sentience—we should consider interests to be ends towards which energy is expended ("take striving at face value"). Note that I propose that the amount of effort should inform our weighing of interests within an organism, and that I do not here propose that amount of energy expended should inform the weight of total responsibilities to one organism vs. another (an issue addressed in the next section). Even within an organism, other factors may also influence the moral relevance of interests, such as perhaps the extent of conscious direction of a behaviour. For example, if I had a debilitating disease that made continued existence painful and undesirable, my desire to terminate my life should supersede my body's apparent interest in continued life even if I could exert no energy towards that self-destructive end.

Nevertheless, in the absence of direct communication, concerted energy expenditure suggests sentience and may also provide considerable information regarding the strength and context of interests. For example, wolves will devour all the soft tissue on moose carcasses only when vulnerable prey are rare; when they are common, wolves will leave the lower half of the legs, the underside of the carcass, and other less-choice morsels (Peterson and Ciucci 2003). Similarly, when salmon are abundant, wolves will eat only the heads (and bears only the roe) (Byington 2005). These observations suggest that the strength of a wolf's interest in carcass parts correlates with their quality and also is a function of the wolf's own condition and likelihood of further prey capture.

By analyzing the contingency by which organisms pursue proximate goals, we can discern apparent ultimate goals. A being will often pursue $\mathrm{X}$ not because of an interest in $\mathrm{X}$, but because of X's ability to produce Y, which is valued inherently. We find evidence for such instrumental relationships when a being's pursuit of the proximate goal depends on its connection to the 
ultimate goal. For example, that wolves are more concerned with food when they are emaciated suggests that they value food in part for its ability to nourish their bodies. The fact that wolves will regurgitate their food to feed their young (Packard 2003) suggests that - to an extent, and under some circumstances - they value their pups' nourishment over their own (survival is not the ultimate goal). ${ }^{10}$

We need not assume that other organisms have conscious thoughts like ours, but we should leave open the possibility that they have some form of experience and purpose. For example, when a mother bird feigns injury and leads us away from her nest, we need not know that she is conscious in order to respect her apparent purpose. By considering other behaviors (like how she would act if we encountered her further from her nest, or if we approached her nest directly), we can discern her likely purpose: not to perform for us, endanger herself, or leave us alone with her nest, but to draw us away, protecting her eggs or chicks. Similarly, when a plant produces sweet colorful fruits that are consumed by birds, we need not assume that the plant is striving to nourish avian friends. By considering all the other ways in which the plant prepares a seed to germinate in soil fertilized by a bird's excrement, we can discern that the plant's likely purpose is to give her offspring the best possible start to life. The fact that the purposes of non-human organisms are apparently the result of evolution does not eliminate them from consideration. ${ }^{11}$

Although it might seem that such reasoning would be highly demanding conceptually, one should recognize that we must discern underlying goals when dealing with people, also. With people, the train of logic is also often unknown, even to the person in question. For example, a teenager might try a cigarette, not because she enjoys the smell or wishes to incur the various health risks associated with smoking, but because she feels - perhaps subconsciously — that smoking will make her more desirable as a companion or friend. 


\section{How to weigh their possible interests against those of others?}

Above, I argued that our responsibilities are proportional to the probabilities of sentience and consciousness; here we must ask how this might affect the distribution of responsibilities across beings. The probability $p$ of sentience (or consciousness) is a function of physical structures, behaviors, and physiological processes. With probability 1-p, the being is not sentient and by definition cannot care how it is treated, as that cannot make a difference to any experience. Thus, if there is probability $p$ that the being is sentient and would want $\mathrm{X}$, we should include in our calculations the being's apparent interest in X with a weight of $p(0<p<1)$. That is, we should discount a being's possible interests by our uncertainty that it is sentient.

That there are no objective estimates of $p$ is not an insurmountable problem. There is also no precise method for calculating utility or welfare, but this has not prevented utilitarianism from contributing greatly to ethics and to decisions made by public authorities, which are of enormous ethical import. Policy decisions are made often using proxies of utility (usually dollars), which are known to be imperfect. If this framework were to be applied at the policy level, it would likely require proxies for $p$, but at this stage my purpose is merely a defense of the theory. And for application at the level of individual decision-making, subjective probabilities may actually be desirable. 


\section{The Limits of Interpretable Interests (G)}

While we might not exclude any entities from moral consideration based on a presumed lack of sentience, there is reason to exclude inanimate objects based on our inability to interpret their interests. This is a fundamentally different cause for exclusion than physical or behavioural criteria for sentience. Earlier, I argued that there is little if any indication that rocks and other inanimate objects are sentient. My argument here is that even if we believe that there is a miniscule but non-zero probability that such objects are sentient, this confers no duties on us unless we can interpret possible interests.

Objects that cannot act and apparently cannot sense their environment do not provide any clues regarding what their interests might be: we cannot feasibly ascertain what would benefit them. Many objects seem to fall in this "inanimate" category. Electrons move, but their movement is governed entirely by physical forces acting on them. Stars "burn" energy through chemical reactions, but there is no coordination or control over these processes, and the energy is not harnessed to achieve any end. Accordingly, one cannot even say that "they burn energy", as they are only the location at which these processes occur. The same is true for genes and prions: although they may appear selfish (Dawkins 1976), this is purely because they have structures that happen to result in them being replicated by the actions of cells and other molecules, not because they act on their own. ${ }^{12}$ In the face of an absence of information regarding interests, attempting to interpret or imagine interests is an unwarranted distraction from our duties to others.

Following the above discussion, I tentatively propose the following criteria for the interpretability of interests: physical cohesion and the capacity for coordinated ${ }^{13}$ and autonomous action. This 
practical boundary is critically different from lines drawn because acknowledging responsibilities beyond the line would be too restrictive to human actions, as argued by Warren (1997).

\section{The Interests of Non-Human Organisms $(\mathrm{H}, \mathrm{I})$}

The possession of interests is often considered to be dependent on sentience, but as we are considering beings for which sentience is uncertain or even quite improbable, here I refer to the possible interests of such beings as simply 'interests' in order to avoid a constant stream of qualifiers (I will later incorporate the strength of evidence for sentience).

As mentioned above, I consider an organism's interests to be the ends for which it strives/expends effort, a definition that has several advantages. Because I avoid referring to historic adaptation or natural selection in identifying interests — as does Varner $(1998)^{14}$ — I simplify the criteria for interests and remove problems associated with artificial selection (selective breeding by humans). Varner's theory is challenged by cases in which a behavior would be identified as being in an organism's interest even if an environmental change renders the behavior damaging to the organism's survival or reproductive success. Under the Golden Rule, we can recognize that an organism's behaviors generally reflect its interests, but that all organisms — including people_occasionally err.

Given that we seem to have duties to respect the interests of non-human organisms, it is worth considering what their ultimate interests might be. They are not simply survival. There are countless organisms who endanger or sacrifice themselves for their young (Crawley et al. 1985), like the mother bird who draws intruders away from her nest or cichlid fish who fast for weeks because they are holding their young protectively in their mouths (Barlow 1991). Their purpose 
is also not simply reproduction, in the sense of bearing their own children. There are numerous organisms, including social ants and bees, birds, canids, felines, ground squirrels, etc., who will sacrifice their condition and/or reproductive opportunities in order to help raise genetic relatives who are not direct descendants (Crawley et al. 1985; Sherman 1977; Skutch 1935; 1961). The more similar the genes, the greater the effort that an organism is likely to expend in order to help another organism. ${ }^{15}$ Masses of biological data in the form of various behaviors suggest that if living beings had a purpose, it would be to maximize the future representation of their genetic lineages (in biological terms, their inclusive fitness) ${ }^{16}$ Elsewhere I consider this possible ultimate interest in genetic continuity in much more detail. ${ }^{17}$ Having inferred ultimate goals based on biological observation, we can generally consider a behavior to be in an organism's true interests if it increases that organism's inclusive evolutionary fitness. This does not define the whole set of organisms' interests, however. One can train chickens to shun a staple food by associating the food with an aversive or painful experience (e.g., Atkinson et al. 2003), which suggests that chickens have an inherent interest in avoiding pain. Falcons, dogs, dolphins, and numerous other animals appear to grieve lost loved ones, sometimes to the point that it threatens their own survival, which suggests that they have an interest in avoiding emotional kinds of pain as well (Moussaieff Masson and McCarthy 1995). Elephants in particular display emotional interests very similar to our own, for example by going out of their way to return to the bones of herd mates and fondle these bones with their trunks (Moss 1988).

How can we distinguish between "mistaken" interests and interests in things other than maximizing inclusive fitness? For example, when an organism ingests something poisonous, how can we know whether it was mistaken, 'wished' to die, or valued the experience of the poison more than life? This troublesome issue is not unique to non-human organisms, but also plagues 
efforts to capture the welfare of persons (e.g., euthanasia). We can rely upon parallel physiological evidence and the consistency of behaviors in order to distinguish "mistaken" from inherent interests. I will not go into further detail on this point except to point out that in practice we do make these difficult calls. For example, pet owners routinely administer medical treatments that appear to involve forcing animals to endure considerable discomfort for their long-term interests. In such cases, we judge that while pets have an interest in not being force-fed large pills, they are mistakenly failing to pursue greater interests in long-term health because of ignorance of the beneficial effects of the medication.

\section{Categorizing Organisms for Application (J)}

Consideration of the implications of this argument for different levels of biological organization will require a separate analysis, but it is worth sketching out how we might weigh different interests. As I have already argued, we should assign different weight to the interests of different organisms according to the strength of evidence in favor of their sentience. Here I elaborate on that weighting for various entities, grouped into classes purely for convenience of explanation.

These are not levels in a moral hierarchy. There is nothing but the estimated probabilities of sentience and consciousness that prevent the interests of organisms in simpler levels from outweighing those in higher levels. A more thorough consideration of such cases is an important next step, but it involves additional complexity and is thus beyond the scope of the current paper.

At the first level are entities capable of sensing their environment and responding with simple coordinated actions. Examples would be single-cellular organisms such as bacteria, amoebae, phytoplankton, etc. It does seem unlikely that such organisms have a point of view, given that 
even our simplest sensations seem to occur through the communication of numerous cells. It seems likely that single-celled entities are not sentient, but again such organisms may have a sentience quite different from our own, possibly based on communication between organelles rather than cells.

At the second level are entities capable of more complicated actions involving the communication and coordination of various cells, but in which environmental impacts trigger reactions directly. In such organisms, like multi-cellular plants, fungi, and simple invertebrate animals, there is an additional level of organization, which might yield some kind of experience. Yet these beings still lack secondary processing of signals: there are no centers of communication at which multiple units send chemical messages, and which in turn send messages to multiple units. Without central processing, any sensations would likely be incredibly simple and unlinked. For these simple multi-cellular organisms, we have some evidence of sensations but little suggestion of a coordinated perspective.

At the third level are entities that possess secondary signal processing but no single central processing unit. In organisms of this category, including insects and earthworms and other medium-complexity invertebrates, there is clear coordination of communication at nerve ganglia. While it is quite plausible that such organisms have a perspective, it would likely be a rather different - more disconnected - perspective than our own, owing to the multiple ganglia acting somewhat separately and the lack of a single dominant processing unit.

At the fourth level are entities with central tertiary signal processing but no obvious consciousness. Such organisms — which include simpler vertebrates and some invertebrateshave a brain, but have not been shown capable of mental representations of objects. This central 
nervous system receives inputs from and coordinates actions through various nerve ganglia. It is almost impossible to believe that such organisms do not have perspectives that include experiences of several sensations very similar to our own.

At the fifth level are entities shown to have mental representations of objects that allow them to plan for the future. Organisms in this category - including octopi and other cephalopods, ${ }^{18}$ dogs, cats, pigs, etc. - seem to have conscious thought and perhaps emotions akin to ours. Behaviors like dreaming (e.g., Chadwick 1992; Darwin 1872, reprint) are evidence of their mental representations and strongly suggest experiences quite similar to our own.

There are also additional levels with various kinds of self-awareness (DeGrazia 1996), rationality, etc. Such levels are possibly restricted to humans and higher primates, ${ }^{19}$ but they might include dolphins, ${ }^{20}$ elephants, lions, ${ }^{21}$ birds, ${ }^{22}$ and others. There is little question that these beings have ultimate interests and that these interests matter.

The various levels of sentience actually have two types of impact on levels of responsibility. Not only does the likelihood of experience vary, so does the range, complexity, and strength of interests. ${ }^{23}$ Organisms at the first two levels seem to have no ultimate interests save perhaps maximizing genetic representation. At the third and fourth levels, it appears that organisms also value particular sensations such as pleasure. At the fifth level, organisms seem to value future events and emotions (i.e., more complex sensations, such as the grief of elephants, empathy of rhesus monkeys (Masserman et al. 1964), and the anticipation and joy of rats (Panksepp and Burgdorf 2003)), which places additional value on continued life. At the sixth level and beyond, beings explicitly value their own experience of existence. 
As the range, complexity, and intensity of a being's apparent interests increase, so do the range, complexity, and intensity of our responsibilities to them. Stories of solitary animals being so overcome with loneliness or grief that they appear to lose the will to live-and of sometimes being rescued by a new companion (Moussaieff Masson and McCarthy 1995)—suggest that emotions are a critical component of animal well-being. If animals anticipate and express preferences regarding the experience of future events — as rats seem to do ${ }^{24}$ - we have additional reasons to protect their lives.

At the lower levels of sentience, we seem to have relatively little direct responsibility to individual organisms. Such organisms are no more capable of coordinated action than are component cells of more complex organisms, so they seem to merit no more consideration than do such cells when they turn renegade and act against the interests of the whole organism (e.g., cancer cells). Clearly, this analysis of the extensionist ethics does not entail equal consideration of all living beings.

Because this article establishes a basis for extending consideration to non-human organisms and not a particular ethical theory, I do not advance many particular normative implications. Several implications do follow, however. For example, this argument suggests - in contrast to many people's attitudes - that we owe some consideration to insects and other 'simple' invertebrate organisms. It suggests that animal welfare organizations should be concerned not only with actions that undermine the well-being of individual mammals and birds, but also with those that affect large numbers of 'lower' organisms. It suggests that any ethics process — such as animal care ethics certification at universities — ought not to draw firm boundaries at 'higher' organisms such as vertebrates (as is common practice), but rather they ought to place constraints on actions that affect large numbers of 'lower' organisms, including plants. 


\section{Conclusion}

I have argued that extensionist ethics should be revised in the following way: In determining the strength of our responsibilities, we should incorporate our uncertainty of sentience and consciousness as continuous variables, not categorical ones. From this persistent uncertainty of mental phenomena comes certainty of responsibilities to non-human organisms, although these responsibilities are discounted by the uncertainty. Accordingly, we have stronger responsibilities to more complex entities due to greater evidence of sentience and consciousness. Because these duties stem from empathy for the interests of individuals, this version of ethical extensionism provides a foundation for an environmental ethic that is compatible with interpersonal and animal welfare ethics. Although the implications of this approach will depend strongly on the particular ethical theory being extended, it does suggest much greater consideration for beings often dismissed as 'lower'.

\section{Acknowledgements}

I am deeply grateful to several anonymous reviewers and various colleagues for their input on various earlier versions of this paper: David Fraser (especially), Michael Barkusky, Isis Brook, Nigel Haggan, Gaverick Matheny, Susanne Menzel, Bruce Morito, Bryan Norton, Anton Pitts, Peter Singer, Ingrid Stefanovic, Sandra Tomsons, Nathan Vadeboncoeur, and the Chan lab at UBC. 


\section{Notes}

${ }^{1}$ For example, Warren (1997, p.37) writes, "it is reasonable to conclude that terrestrial organisms which lack nervous systems are probably incapable of having conscious experiences."

${ }^{2}$ There are many who differ. See e.g., Feinberg (1974, p. 55), who claims that speaking of "weeds flourishing . . . is a plain piece of irony".

${ }^{3} \mathrm{I}$ am grateful to an anonymous reviewer for the idea to express these ideas in notation.

${ }^{4}$ Viruses tend not to have ATP, the molecule commonly used to transport energy. When viruses replicate, the ATP and other molecules necessary for replication are borrowed from host cells. Accordingly, most processes crucial to viral life cycles occur outside the viral coat. This characteristic does not prove that viruses do not have experiences of their own, but it does reduce the plausibility of such experiences.

${ }^{5}$ Many cultures seem to invoke points-of-view in most other living things: (Abram 1996)

${ }^{6}$ It is not immediately apparent how to identify equivalent interests of different beings, but a default method might be to employ the same criteria that allow us to discern strength of interests within entities: the amount and the contingency of effort expended towards fulfillment of the interest.

${ }^{7}$ Applied to non-human organisms, 'affective state' is the technical term for emotions and feelings, which is used to avoid concerns of anthropomorphizing.

${ }^{8}$ Dawkins (1980) represents an exception: Dawkins seems to consider the ultimate ends important in and of themselves even if animals are unaware of them. She seems to equate ultimate factors with long-term well-being; proximate factors may contribute to these ends orincreasingly likely in artificial environments - not. 
${ }^{9}$ This is a procedural application of the Golden Rule, not a substantive one: it helps us determine how we should decide on duties to others, not the content of those duties (except through the process).

${ }^{10}$ Similar reasoning helps resolve the possible quandary concerning the component cells of multi-cellular organisms. According to the criteria proposed above, such cells seem to qualify as entities that might possess a perspective, but accounting for their individual interests might impossibly complicate an ethical system. Fortunately, it seems that in the vast majority of cases (except for rogue cells like cancer cells), such component cells coordinate their efforts entirely for the interests of the organism as a whole. Accordingly, we usually need not consider component cells separately. Even if we considered interests at the level of component cells, conflicts like cancer would be easily resolved because the interests of cooperative cells would overwhelmingly outweigh those of the cancer cells: the interests of the cells as a group would coincide with the interests of the organism and favor treatment of the disease.

${ }^{11}$ At one level, ants carry the colony's eggs and larvae to safety because more selfish colonies perished historically (i.e., through evolution due to natural selection). This fact does not demonstrate that ants have no perspective or interests worth considering. Indeed, observation of our closest primate relatives suggests that our own most cherished emotions - and thus many of our own purposes — evolved through this same process. That our experiences of love and happiness are internalized products of evolution does not diminish the interests that stem from these emotions.

${ }^{12}$ A more difficult case for the Golden Rule is the class of animate objects, cars and other mechanical objects in which there is coordination of processes and energy harnessed towards an end. In general, I agree with Mary Anne Warren (1997, p.18) that our moral obligations to 
sentient or self-aware machines seem just as great as to biological organisms "with comparable mental and behavioural capacities", but it is worth considering the ramifications of this for particular contemporary objects. First, there are objects that initiate no action, and whose response pathways are controlled directly by human drivers and designers. Because of this, we have no evidence of a car's own interests, so no way to know what would benefit it. Second, slightly more complicated are objects like thermostats, which can — to a degree — sense and respond automatically to the environment. (Of course, cars now possess several different systems where responses are automatic, including thermostats.) One might speculate that a thermostat's desire is to keep the room at the set temperature. Although this is our interest programmed directly into the thermostat, that is not to say it is not also the interest of the thermostat. But the evidence in favor of the thermostat's preference is extremely limited: there is but a single programmed response with no possibilities for contingencies. Because of this, these response pathways are also controlled directly by human engineers, so these objects are not autonomous. (By "autonomous", I mean that actions do not clearly result immediately and automatically from the will of another being.)

Even more difficult and interesting are cases like advanced chess programs and robots imbued with artificial intelligence. In these cases, some responses are not pre-programmed; designers program the way that these applications and objects will learn to respond. (I am grateful to an anonymous reviewer for the example of advanced chess programs.) Because of the complexity and contingency of responses, the evidence in favor of sentience here is greater, although still limited. Future robots will almost certainly have added complexity, providing interesting ethical dilemmas. A full treatment of this issue is beyond the scope of the present paper; here it is sufficient to note that there is no apparent need for DNA or self-replication in 
order for an entity to be sentient or merit consideration. There are already anthropogenic objects that seem to merit the level of consideration attributed to individual simple biological organisms, but as I discuss in the following section, this does not entail much.

${ }^{13}$ By “coordinated", I mean multiple actions-perhaps of different components (such as organelles) - are not working at cross purposes.

${ }^{14}$ Similarly, Barnard and Hurst (1995) include natural selection in their notion of welfare.

15 as expressed theoretically by (Hamilton 1963); for extensive empirical evidence, see references in (Agrawal 2001).

${ }^{16}$ Note that human beings are rather more complex; I do not seek to make sense of their ultimate interests and the extent to which the continuation of genetic lineage plays a role.

${ }^{17}$ Chan, K. M. A. In preparation. "Concern for species derived from individual-level duties". ${ }^{18}$ (Boal et al. 2000; Fiorito and Scotto 1992; Karson et al. 2003). I'm grateful to an anonymous reviewer for highlighting this point.

${ }^{19}$ The ability of chimpanzees (Gardner et al. 1989) and gorillas (Patterson and Linden 1981) to learn sign language is an indication of the mental complexity of these great apes. The question of whether non-human primates possess a theory of mind (an understanding that other organisms have minds) has generated great controversy. While some researchers have argued that no nonhuman organism has such capability based on a restrictive all-or-nothing conception of theory of human mind (e.g., Povinelli and Bering 2002), recent evidence suggests quite clearly that animals of various species behave as if they have a theory of mind in various circumstances (Call and Tomasello 2008; Shettleworth 2009), for conspecific organisms and also human beings. Such research is highly instructive for interspecies ethics, but theory of mind is but one cognitive capacity of importance to ethics, and evidence for or against this capacity in some circumstances 
reveals little about an organism's capacity in other circumstances (e.g., several organisms seem to understand perception and knowledge in conspecific organisms but not - in several contexts-in human beings) (Shettleworth 2009).

${ }^{20}$ For recent evidence suggesting reasoning and culture in dolphins`, see Kuczaj and Highfill (2005)

${ }^{21}$ Which hunt cooperatively in ways that suggest an ability to anticipate and coordinate with the behavior of others (Stander 1992).

${ }^{22}$ Ravens (Bugnyar and Heinrich 2005), scrub jays (Dally et al. 2006), and jackdaws (von Bayern and Emery 2009) all display social skills that suggest some components of a theory of mind (Shettleworth 2009) with conspecific organisms or humans.

${ }^{23}$ For discussions of these issues, see (Regan 1983; Singer 1991; 1993).

${ }^{24}$ This ability even extends — in abundance — to rats, as discussed by Panksepp (2003)

\section{References}

Abram, D. 1996. The Spell of the Sensuous: Perception and Language in a More-Than-Human World. New York, NY: Vintage Books.

Agrawal, A. F. 2001. 'Kin recognition and the evolution of altruism'. Proceedings of the Royal Society Biological Sciences Series B 268(1471): 1099-1104.

Atkinson, R., L. R. M. Bevilaqua, J. A. P. Rostas and M. Hunter. 2003. 'Discriminative taste aversion learning: A learning task for older chickens'. Neurobiology of Learning and Memory 79(1): 25-31.

Attfield, R. 1999. The Ethics of the Global Environment. Edinburgh: Edinburgh University Press.

Barlow, G. W. 1991. 'Mating systems among cichlid fishes', in: M. H. A. Keenleyside ed. Cichlid Fishes: Behaviour, Ecology and Evolution (New York, NY: Chapman \& Hall), pp. 173190.

Barnard, C. J. and J. L. Hurst. 1995. 'Welfare by design: The natural selection of welfare criteria'. Animal Welfare 5(4): 405-433.

Bentham, J. 1823. An Introduction to the Principles of Morals and Legislation. London, UK: W. Pickering. 
Birch, T. H. 1993. 'Moral considerability and universal consideration'. Environmental Ethics 15(4): 313-332.

Bugnyar, T. and B. Heinrich. 2005. 'Ravens, Corvus corax, differentiate between knowledgeable and ignorant competitors'. Proceedings of the Royal Society B: Biological Sciences 272(1573): 1641-1646.

Byington, C. 2005. 'Spirit of the Great Bear rainforest'. Nature Conservancy, pp. 36-50.

Callicott, J. B. 1985. 'Intrinsic value, quantum theory, and environmental ethics'. Environmental Ethics 7(3): 257-275.

Chadwick, D. H. 1992. The Fate of the Elephant. New York, NY: Random House.

Crawley, J. N., M. E. Sutton and D. Pickar. 1985. 'Animal-models of self-destructive behavior and suicide'. Psychiatric Clinics of North America 8(2): 299-310.

Dally, J. M., N. J. Emery and N. S. Clayton. 2006. 'Food-caching western scrub-jays keep track of who was watching when'. Science 312(5780): 1662-1665.

Darwin, C. 1872, reprint. The Expression of Emotion in Man and Animals. McLean, VA: IndyPublish.com, 2005.

Dawkins, M. S. 1980. Animal Suffering: The Science of Animal Welfare. London: Chapman and Hall.

Dawkins, R. 1976. The Selfish Gene. Oxford: Oxford University Press.

DeGrazia, D. 1996. Taking Animals Seriously: Mental Life and Moral Status. Cambridge, UK: Cambridge University Press.

Dennett, D. C. 1991. Consciousness Explained. Boston, MA: Little, Brown \& Co.

Diamond, C. 2008. 'The difficulty of reality and the difficulty of philosophy', in: S. Cavell, C. Diamond, J. McDowell, I. Hacking and C. Wolfe eds. Philosophy and Animal Life (New York: Columbia University Press), pp. 43-89.

Feinberg, J. 1974. 'The rights of animals and unborn generations', in: J. Feinberg ed. Rights, Justice, and the Bounds of Liberty: Essays in Social Philosophy (Princeton, NJ: Princeton University Press), pp. 159-184.

Gardner, R. A., B. T. Gardner and T. E. Van Cantfort eds. 1989 Teaching Sign Language to Chimpanzees (Albany, NY: State University of New York Press, 1989), p. 324.

Gershenzon, J. and N. Dudareva. 2007. 'The function of terpene natural products in the natural world'. Nature Chemical Biology 3(7): 408-414.

Gorke, M. 2003. The Death of Our Planet's Species: A Challenge to Ecology and Ethics. Washington, DC: Island Press.

Griffin, D. R. 2001. Animal Minds: Beyond Cognition to Consciousness. Chicago: University of Chicago Press.

Hamilton, W. D. 1963. 'The evolution of altruistic behavior'. The American Naturalist 97: 354356.

Jamieson, D. 2002. Morality's Progress: Essays on Humans, Other Animals, and the Rest of Nature. Oxford: Oxford University Press.

Kuczaj, S. A. and L. E. Highfill. 2005. 'Dolphin play: Evidence for cooperation and culture?'. Behavioral and Brain Sciences 28(5): 705-706.

Loewenstein, G. F. and T. O'Donoghue. 2004. Animal Spirits: Affective and Deliberative Processes in Economic Behavior. SSRN.

Masserman, J. H., S. Wechkin and W. Terris. 1964. '"Altruistic" behavior in rhesus monkeys'. The American Journal of Psychiatry 121: 584-585. 
Maye, A., C.-h. Hsieh, G. Sugihara and B. Brembs. 2007. 'Order in Spontaneous Behavior'. PLoS ONE 2(5): e443.

Midgley, M. 1998. Animals and Why They Matter. Athens, GA: University of Georgia Press.

Milinski, M. and B. Rockenbach. 2007. 'Spying on others evolves'. Science 317(5837): 464-465.

Moss, C. 1988. Elephant Memories: Thirteen Years in the Life of an Elephant Family. New York, NY: W. Morrow.

Moussaieff Masson, J. and S. McCarthy. 1995. When Elephants Weep: The Emotional Lives of Animals. New York, NY: Delacorte Press.

Nagel, T. 1974. 'What is it like to be a bat?'. Philosophical Review 83(4): 435-450.

Packard, J. M. 2003. 'Wolf behavior: reproductive, social, and intelligent', in: L. D. Mech and L. Boitani eds. Wolves: Behavior, Ecology, and Conservation (Chicago: University of Chicago Press), pp. 35-65.

Panksepp, J. and J. Burgdorf. 2003. "'Laughing" rats and the evolutionary antecedents of human joy?'. Physiology \& Behavior 79(3): 533-547.

Patterson, F. and E. Linden. 1981. The Education of Koko. New York, NY: Holt, Rinehart, and Winston.

Peterson, R. O. and P. Ciucci. 2003. 'The wolf as a carnivore', in: L. D. Mech and L. Boitani eds. Wolves: Behavior, Ecology, and Conservation (Chicago: University of Chicago Press), pp. 104-130.

Povinelli, D. J. and J. M. Bering. 2002. 'The mentality of apes revisited'. Current Directions in Psychological Science 11(4): 115-119.

Regan, T. 1983. The Case for Animal Rights. Berkeley: University of California Press.

Regan, T. 1992. 'Does environmental ethics rest on a mistake?'. Monist 75(2): 161-182.

Rolston, H. I. 1988. Environmental Ethics: Duties to and Values in the Natural World. Philadelphia: Temple University Press.

Sanfey, A. G., G. Loewenstein, S. M. McClure and J. D. Cohen. 2006. 'Neuroeconomics: crosscurrents in research on decision-making'. Trends in Cognitive Sciences 10(3): 108-116.

Sapontzis, S. F. 1992. Morals, Reason, and Animals. Philadelphia, PA: Temple University Press.

Satpute, A. B. and M. D. Lieberman. 2006. 'Integrating automatic and controlled processes into neurocognitive models of social cognition'. Brain Research 1079: 86-97.

Sherman, P. W. 1977. 'Nepotism and the evolution of alarm calls'. Science 197(4310): 12461253.

Shettleworth, S. J. 2009. 'The evolution of comparative cognition: Is the snark still a boojum?'. Behavioural Processes 80(3): 210-217.

Singer, P. 1979. 'Not for humans only: The place of nonhumans in environmental issues', in: K. E. Goodpaster and K. M. Sayre eds. Ethics and Problems of the 21 st Century (Notre Dame, Indiana: University of Notre Dame Press), pp. 191-206.

Singer, P. 1991. Animal Liberation. New York: New York Review of Books.

Singer, P. 1993. Practical Ethics. Cambridge, UK: Cambridge University Press.

Skutch, A. F. 1935. 'Helpers at the nest'. Auk 52: 257-273.

Skutch, A. F. 1961. 'Helpers among birds'. Condor 63(3): 198-226.

Stander, P. E. 1992. 'Cooperative hunting in lions: The role of the individual'. Behavioral Ecology and Sociobiology 29(6): 445-454.

Taylor, P. W. 1986. Respect for Nature: A Theory of Environmental Ethics. Princeton, NJ: Princeton University Press. 
Varner, G. E. 1998. In Nature's Interests? Interests, Animal Rights, and Environmental Ethics. Oxford, UK: Oxford University Press.

von Bayern, A. M. P. and N. J. Emery. 2009. 'Jackdaws respond to human attentional states and communicative cues in different contexts'. Current Biology 19(7): 602-606.

Warren, M. A. 1997. Moral Status: Obligations to Persons and Other Living Things. Oxford, UK: Oxford University Press

Wise, S. M. 2002. Drawing the Line: Science and the Case for Animal Rights. Cambridge, Mass: Perseus Books. 